\title{
Two-step calculation method to enable the ecological and human health risk assessment of remediated soil treated through thermal curing
}

\author{
Shaowen $\mathrm{Xie}^{1,2}$, Fei $\mathrm{Wu}^{2}$, Zengping $\mathrm{Ning}^{3}$, Manjia Chen ${ }^{2}$, Chengshuai $\mathrm{Liu}^{2,3, *}$, Qiang Huang ${ }^{5}$, \\ Fangyuan Meng ${ }^{3,4}$, Yuhui Liu ${ }^{3,4}$, Jimei Zhou ${ }^{3,4}$, Yafei Xia ${ }^{3,4}$
}

1 School of Environmental and Chemical Engineering, Foshan University, Foshan 528000, China

2 National-Regional Joint Engineering Research Center for Soil Pollution Control and Remediation in South China, Guangdong Key Laboratory of Integrated Agro-environmental Pollution Control and Management, Institute of Eco-environmental and Soil Sciences, Guangdong Academy of Sciences, Guangzhou 510650, China

3 State Key Laboratory of Environmental Geochemistry, Institute of Geochemistry, Chinese Academy of Sciences, Guiyang 550081, China 4 University of Chinese Academy of Sciences, Beijing 100049, China

5 School of Food Science and Engineering, Foshan University, Foshan 528000, China

\section{H I G H L I G H T S}

- Remediated soil treated by thermal curing exhibited strong inherent resistance to acidic attack with the formation of $\mathrm{ZnCr}_{2} \mathrm{O}_{4}$ spinel.

- A two-step method to calculate the sum of the leaching and acid-soluble fraction contents of $\mathrm{Zn}$ in remediated soil for risk evaluation have been proposed.

- Compared with the traditional one-step calculation method, this two-step calculation method can effectively avoid underestimating the risk of remediated soils.

\section{ARTICLE INFO}

Article history:

Received December 9, 2020

Revised March 17, 2021

Accepted April 17, 2021

\section{Keywords:}

Remediated soil

Heavy metal

Leaching agent $\mathrm{pH}$ value

Fraction distribution

Ecological and human health risk

\section{GRAPHICAL ABSTRACT}

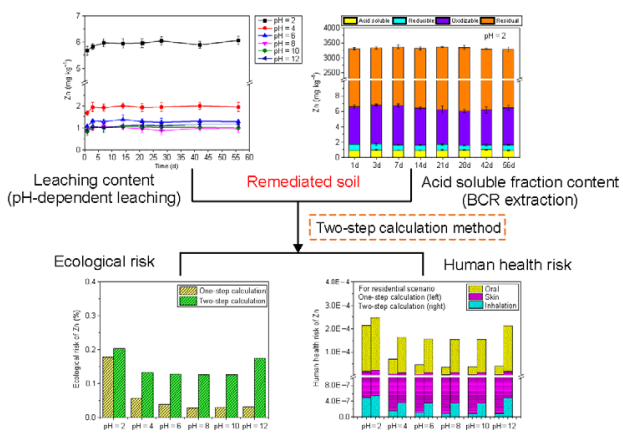

A B S T R A C T

The centralized utilization of heavy-metal-contaminated soil has become the main strategy to remediate brownfield-site pollution. However, few studies have evaluated the ecological and human health risks of reusing these remediated soils. Considering $\mathrm{Zn}$ as the target metal, systematic $\mathrm{pH}-$ dependent leaching and the Community Bureau of Reference (BCR) extraction were conducted at six $\mathrm{pH}$ values $(\mathrm{pH}=2,4,6,8,10,12)$ for the remediated soil treated through thermal curing. The $\mathrm{pH}$ dependent leaching results showed that with the formation of $\mathrm{ZnCr}_{2} \mathrm{O}_{4}$ spinel phases, the remediated soil exhibited strong inherent resistance to acidic attack over longer leaching periods. Furthermore, the $\mathrm{BCR}$ extraction results showed that the leaching agent $\mathrm{pH}$ value mainly affected the acid-soluble fraction content. Moreover, a strong complementary relationship was noted between the leaching and acid-soluble fraction contents, indicating that the sum of these two parameters is representative of the remediated soil risk value. Therefore, we proposed a two-step calculation method to determine the sum of the two heavy metal parameters as the risk value of remediated soil. In contrast to the traditional one-step calculation method, which only uses the leaching content as the risk value, this two-step calculation method can effectively avoid underestimating the risk of remediated soil.

\footnotetext{
* Corresponding author

E-mail address: liuchengshuai@vip.gyig.ac.cn (C. Liu)
} 


\section{Introduction}

With the acceleration of urbanization and industrial transformation, many old factories are facing closure or relocation, leaving behind soils with significant heavy metal contamination, and such soils have attracted increasing research attention worldwide (Khalid et al., 2017; Xie et al., 2019). The hazardous metals, such as zinc ( $\mathrm{Zn})$, chromium ( $\mathrm{Cr}$ ), lead $(\mathrm{Pb})$, copper $(\mathrm{Cu})$ and cadmium $(\mathrm{Cd})$, present in these site soils can be attributed to the industrial emissions, traffic emissions, and mining activities (Luo et al., 2012). These heavy metals are nonbiodegradable and thus persist in soils, thereby affecting the yield and quality of farm crops and posing a significant risk to human health (Fu et al., 2012; Sun et al., 2019). However, in the context of ensuring sustainable development and alleviating the shortage of soil resource, these brownfield sites must be necessarily subjected to secondary development (Wang et al., 2018; Vareda et al., 2019). Therefore, effective remediation technologies and corresponding risk evaluation methods must be identified to evaluate the potential ecological and human health risks of remediated soils in different actual reuse scenarios.

Until now, many techniques has been developed to remediate heavy-metal-contaminated brownfield-site soils, such as physical, chemical and biological remediation (Kumpiene et al., 2008; Yao et al., 2012). Thermal curing, based on the fraction transformation through high-temperature sintering, is a notable heavy-metal-contaminated soil remediation technology because of its high efficiency and practical advantages (Samaksaman et al., 2016; Li et al., 2019). Through thermal curing, the hazardous metals in contaminated soils can be incorporated into spinel crystal structures and reused as building materials such as bricks in residential and industrial scenarios (Tang et al., 2011; Guo et al., 2017). Spinels are usually expressed using the general formula " $A B_{2} \mathrm{O}_{4}$," where " $A$ " represents divalent metals such as $\mathrm{Zn}, \mathrm{Cu}, \mathrm{Cd}$ or $\mathrm{Ni}$, and "B" represents trivalent matrix metals such as $\mathrm{Cr}$ or Al (Marinković et al., 2004). Spinels have been recognized as a promising crystal structure in which a variety of divalent metals can be incorporated and exist stably in the obtained sintered products for a long time (Shih et al., 2006; Tang et al., 2016).

After heavy metals are stabilized in a spinel structure, their leaching potential is significantly reduced (Taha et al., 2018; Ding et al., 2019). For example, when $\mathrm{ZnO}$ is sintered (to simulate zinc-laden ash) with kaolinite and mullite ceramic precursors, both zinc aluminate spinel $\left(\mathrm{ZnAl}_{2} \mathrm{O}_{4}\right)$ and willemite $\left(\mathrm{Zn}_{2} \mathrm{SiO}_{4}\right)$ phases can be observed in the products. The leachability of the potential product phases indicates that the zinc contents in $\mathrm{ZnO}$ and $\mathrm{Zn}_{2} \mathrm{SiO}_{4}$ leachates are approximately two orders of magnitude higher than those in $\mathrm{ZnAl}_{2} \mathrm{O}_{4}$ leachate (Shih and Tang, 2012). Spinels demonstrate a considerably higher inherent resistance to acidic attack than metal oxides under leaching, and thus, the spinel incorporation strategy has been noted to be beneficial in stabilizing hazardous metals (Tang et al., 2014). However, the leaching content only reflects the cation-proton exchange mechanism in the metal leaching of remediated soil. Certain doubts remain regarding the potential release of heavy metals due to geochemical fraction changes in the complex reuse environment, as well as the subsequently generated ecological and human health risks during the long-term reuse process (Malviya and Chaudhary, 2006; Liu et al., 2018). Stakeholders in the reuse process of remediated soil are mostly concerned about the fate of heavily contaminated soil and the evaluation of its environmental effect because of the potential detrimental effects on the ecological security and human health. Therefore, environmental risk assessment guidelines for remediated soils from brownfield sites are necessary and becoming increasingly stringent.

The risk values associated with remediated soil reuse in actual complex environmental conditions are key to evaluate the corresponding ecological and human health risks. Almost all the existing ecological and human health risk evaluation models are based on the use of risk values to determine the risk level (Yang et al., 2018). In recent decades, several onestep methods have been reported, in which the calculated leaching content (determined through leaching tests) is used to represent the risk value of remediated soils (Ding et al., 2019). These methods mainly include the toxicity characteristic leaching procedure (TCLP), synthetic precipitation leaching procedure (SPLP) and multiple extraction procedure (MEP), which were issued by the US Environmental Protection Agency (USEPA) and are widely used in the current methods to evaluate the effect of soil remediation technologies (Abbas et al., 2018; Mahedi and Cetin, 2019). If the leaching contents of heavy metals are lower than the relevant toxicity standards under specific experimental conditions, the method is considered to be in accordance with the remediation requirements (Gupta et al., 2019). The risk of heavy metals in remediated soils includes both the short-term leaching risk and long-term release risk. However, the traditional one-step calculation methods are usually based on the leaching contents of heavy metals released under strong acid conditions, such as those involving a specific $\mathrm{pH}$ of 2-3, and thus represent only the short-term leaching risk of the remediated soil. It is difficult to characterize the long-term release risk of heavy metals under complex environmental $\mathrm{pH}$ conditions, and the environmental risk may be underestimated by simply considering the leaching content as the risk value (Taha et al., 2019). In addition, these methods focus only on the effect of the remediation technology and do not extensively consider the ecological and human health risk implications of these remediated soils in the reused environment. Therefore, it is particularly important and urgent to establish a more suitable risk value calculation method to evaluate the ecological and human health risks of remediated soil in different actual reuse scenarios.

In this study, considering $\mathrm{Zn}$ as the target metal, systematic $\mathrm{pH}$-dependent leaching and Community Bureau of Reference $(B C R)$ extraction were conducted at six $p H$ values $(\mathrm{pH}=2,4$, 
$6,8,10$ and 12) for remediated soil treated through thermal curing. The leaching and fraction distribution stability were examined, and a suitable risk value calculation method for the ecological and human health risk evaluation of remediated soil was proposed. Specifically, the objectives of this study were to 1) explore the leaching and fraction distribution stability characteristics of $\mathrm{Zn}$ in remediated soil at different $\mathrm{pH}$ values; 2 ) propose a suitable risk value calculation method for environmental risk assessment; and 3) compare the differences in the risk assessment results between the new risk value calculation method and traditional one-step calculation method.

\section{Materials and methods}

\subsection{Thermal curing}

Among the hazardous metals found in brownfield-site soils, $\mathrm{Zn}$ is one of the most concerning and in need of remediation (Li et al., 2014; Zhou et al., 2017). In a previous study, we observed that $\mathrm{Zn}$ could be incorporated into a $\mathrm{ZnCr}_{2} \mathrm{O}_{4}$ spinel structure by sintering $\mathrm{Zn}$-enriched artificial soils (Wu et al., 2019). Thus, considering $\mathrm{Zn}$ as the target metal, soil that was critically polluted with $\mathrm{Zn}$ was artificially prepared, and coal gangue and shale (at a mass ratio of $1: 3$ ) were added as auxiliary materials to sinter the mixed polluted soil into bricks. The polluted soil was made of $10 \mathrm{~g}$ of a $\mathrm{ZnO}+\mathrm{Cr}_{2} \mathrm{O}_{3}$ mixture ( $\mathrm{Zn}: \mathrm{Cr}$ molar ratio of $1: 2$ ) and $90 \mathrm{~g}$ of uncontaminated soil powder. All the powder mixtures were airdried and pressed into pellets under a pressure of $350 \mathrm{MPa}$. Subsequently, the samples were thermally treated at $1300^{\circ} \mathrm{C}$ for a dwell time of $3 \mathrm{~h}$ with a controlled heating and cooling rate of $10^{\circ} \mathrm{C} \mathrm{min}^{-1}$ in a muffle furnace. Moreover, all the original raw materials were digested with $\mathrm{HCl}-\mathrm{HNO}_{3}-\mathrm{HClO}_{4}$, and the initial $\mathrm{Zn}$ content was determined through the inductively coupled plasma optical emission spectrometry (ICP-OES, Optima 8000, Perkin Elmer). It indicates that clean soil was used to prepare contaminated soil, thereby eliminating the influence of $\mathrm{Zn}$ and $\mathrm{Cr}$ in the original soil on the later experiment. The results are summarized in Table 1.

\section{$2.2 \mathrm{pH}$-dependent leaching procedure}

All the sintered samples were ground to pass through a 0.149 $\mathrm{mm}$ sieve, and $\mathrm{pH}$-dependent leaching procedures were performed. A total of six $\mathrm{pH}$ values $(\mathrm{pH}=2,4,6,8,10$ and 12) were considered. According to the solid waste extraction procedure for leaching toxicity of China (HJ/T299-2007), the leaching solution was prepared from a mixture of concentrated sulfuric acid $\left(\mathrm{H}_{2} \mathrm{SO}_{4}\right)$ and concentrated nitric acid $\left(\mathrm{HNO}_{3}\right)$ with a mass ratio of 2:1 (leaching solution $\mathrm{pH}=2,4$, 6 ), and the $\mathrm{pH}$ of the leaching solution was adjusted using sodium hydroxide $(\mathrm{NaOH})$ and deionized water (leaching solution $\mathrm{pH}=8$, 10, 12) (Zhou et al., 2018; Zhang et al., 2020). Each leaching vial was filled with $20 \mathrm{~mL}$ of the leaching solution and $1 \mathrm{~g}$ of the sample powder, and each treatment was repeated three times. The leaching vials were rotated end-over-end at $30 \mathrm{r} \mathrm{min}^{-1}$ for agitation periods ranging from 1 to $56 \mathrm{~d}$. For each sample series, a total of eight samplings were extracted at time intervals of $1 \mathrm{~d}, 3 \mathrm{~d}, 7 \mathrm{~d}, 14 \mathrm{~d}, 21 \mathrm{~d}, 28$ $\mathrm{d}, 42 \mathrm{~d}$ and $56 \mathrm{~d}$. Next, the leachates were filtered through $0.45 \mu \mathrm{m}$ cellulose membranes, and the leaching content of $\mathrm{Zn}$ was determined through ICP-OES.

\subsection{BCR extraction}

The heavy metal fraction was analyzed using the BCR threestep extraction method proposed by the European Community Standards Division (Sahuquillo et al., 1999; Pardo et al., 2004). Specifically, four geochemical fractions of heavy metals were determined, including the acid-soluble fraction, reducible fraction, oxidizable fraction, and residual fraction (Pueyo et al., 2008; Sutherland, 2010). After all the samples were subjected to $\mathrm{pH}$-dependent leaching, all the residual samples were washed with deionized water to ensure the same $\mathrm{pH}$ value conditions, and next, the BCR extraction procedure was conducted. The specific details regarding the BCR extraction method implemented in this study are as follows. After the leaching experiment, each sample was transferred to a $50 \mathrm{~mL}$ centrifuge tube, and different reagents were added to enable continuous extraction. To obtain the acid-soluble fraction, $20 \mathrm{~mL}$ of $0.11 \mathrm{~mol} \mathrm{~L}^{-1} \mathrm{CH}_{3} \mathrm{COOH}$ was added to the sample, which was shaken and extracted for $18 \mathrm{~h}$ and later centrifuged at $9000 \mathrm{r} \mathrm{min}^{-1}$ for $20 \mathrm{~min}$. The supernatant was stored for testing. To obtain the reducible fraction, $20 \mathrm{~mL}$ of $0.5 \mathrm{~mol} \mathrm{~L}{ }^{-1} \mathrm{NH}_{2} \mathrm{OH} \cdot \mathrm{HCl}$ was added to the abovementioned residue, the sample was shaken for $18 \mathrm{~h}$ and centrifuged, and the supernatant was stored for testing. To obtain the oxidizable fraction, $10 \mathrm{~mL}$ of $8.8 \mathrm{~mol} \mathrm{~L}^{-1} \mathrm{H}_{2} \mathrm{O}_{2}$ was slowly added to the abovementioned residue; subsequently, the sample was shaken for $2 \mathrm{~h}$ and heated at $85^{\circ} \mathrm{C}$ in a water bath. After cooling, $40 \mathrm{~mL}$ of $1.0 \mathrm{~mol} \mathrm{~L}^{-1} \mathrm{CH}_{3} \mathrm{COONH}_{4}$ was added, the sample was shaken for $18 \mathrm{~h}$ and centrifuged, and the supernatant was stored for testing. To obtain the residual fraction, the remaining solid residue was washed with deionized water and then digested with $\mathrm{HCl}-\mathrm{HNO}_{3}-\mathrm{HClO}_{4}$ for testing. All the geochemical fraction contents of $\mathrm{Zn}$ were determined through ICP-OES.

\subsection{Risk value calculation}

The risk value is key to evaluate the ecological and human health risks of remediated soils. Almost all the current ecological and human health risk evaluation models are

Table $1 \mathrm{Zn}$ content in raw experimental materials

\begin{tabular}{ccccc}
\hline Heavy metal $\left(\mathrm{mg} \mathrm{kg}^{-1}\right)$ & Uncontaminated soil & Coal gangue & Shale & Mixed soil sample \\
\hline $\mathrm{Zn}$ & $27.7 \pm 3.8$ & $23.0 \pm 1.7$ & $90.6 \pm 5.7$ & $3413.7 \pm 205.6$ \\
\hline
\end{tabular}


based on the risk values that the heavy metals may produce under complex environmental conditions (Yang et al., 2018). For example, the most widely used ecological risk assessment model (RAC) considers the acid-soluble fraction content of heavy metals as the risk value and the proportion of this content relative to the total amount of heavy metals as the potential ecological risk value of heavy metals (Nemati et al., 2011; Li et al., 2018). In the human health risk evaluation model recommended by the technical guidelines for the risk assessment of the soil contamination of land for construction in China (HJ 25.3-2019), the total amount of heavy metals is considered as the risk value, and the sum of the risks generated by the total amount of heavy metals in various exposure pathways related to the human body is considered as the potential human health risk value. In general, the leaching content of remediated soils treated through thermal curing is usually considered as the risk value to calculate the corresponding environmental risks when using the traditional one-step calculation method (Gupta et al., 2019). However, the geochemical fraction distribution of remediated soils is significantly different from that of natural soil. The environmental risk may be underestimated if only the leaching content is considered as the risk value. Therefore, according to the leaching and fraction distribution stability characteristics summarized in this study, the risk value calculation includes two components: the leaching content and the content that may be released due to changes in the fraction distribution of heavy metals. The calculated risk values can be applied in the existing ecological risk and human health risk models to realize risk assessment.

\section{Results and discussion}

3.1 Leaching and fraction distribution stability characteristics of $\mathrm{Zn}$ under different $\mathrm{pH}$ value leaching conditions

Based on the theory of $\mathrm{AB}_{2} \mathrm{O}_{4}$ spinel formation, the molar ratio of $\mathrm{Zn}$ (a divalent ion) to $\mathrm{Cr}$ (a trivalent ion) was set as 1:2, which is stoichiometrically consistent with the ratio of the two metals in the product phase. In the initial stage of $\mathrm{ZnCr}_{2} \mathrm{O}_{4}$ spinel formation, a solid-state reaction occurred between $\mathrm{ZnO}$ and $\mathrm{Cr}_{2} \mathrm{O}_{3}$ due to a nucleation process, leading to the formation of the $\mathrm{ZnCr}_{2} \mathrm{O}_{4}$ spinel with a cubic face structure (Stephen et al. 2007; Dixit et al. 2015). In our previous work, by combining advanced analytical technologies such as X-ray photoelectron spectroscopy and transmission electron microscopy equipped with energy dispersive $\mathrm{X}$-ray spectroscopy (EDX), $\mathrm{ZnCr}_{2} \mathrm{O}_{4}$ spinel was identified in the sintered mixture of $\mathrm{ZnO}+\mathrm{Cr}_{2} \mathrm{O}_{3}$. Furthermore, $70.55 \%$ of the available $\mathrm{Zn}$ was included in a $\mathrm{ZnCr}_{2} \mathrm{O}_{4}$ spinel phase at the lowest temperature $\left(700^{\circ} \mathrm{C}\right)$, while the transformation ratio value of $\mathrm{Zn}$ increased continuously with the temperature until it reached nearly $100 \%$ at $1300^{\circ} \mathrm{C}$ after $3 \mathrm{~h}$. All the incorporation mechanisms of $\mathrm{Zn}$ and $\mathrm{Cr}$ into $\mathrm{ZnCr}_{2} \mathrm{O}_{4}$ spinel have been presented in our previous study and are thus not repeated in this article (Wu et al., 2019).

Figure 1 demonstrates the leaching performance of $\mathrm{Zn}$ under different $\mathrm{pH}$ value leaching conditions, as evaluated through the $\mathrm{pH}$-dependent leaching. The experimental results showed that the leaching contents of $\mathrm{Zn}$ in sintered samples increased with the extraction time and gradually leveled off after one week. Specifically, after one week, the average leaching contents of $\mathrm{Zn}$ were 5.98, 1.95, 1.29, 0.96, 1.02 and $1.10 \mathrm{mg} \mathrm{kg}^{-1}$ as the $\mathrm{pH}$ increased from 2 to 12 . The leaching content of $\mathrm{Zn}$ under acidic conditions was significantly higher than that under alkaline conditions, and the difference was not significant under the alkaline condition. In general, strong acid conditions are more conducive to the release of divalent metal cations such as $\mathrm{Zn}^{2+}$, and $\mathrm{pH}$ neutral conditions impede the release. The leaching content of $\mathrm{Zn}$ was consistently lower than the risk screening value of soil remediation of heavymetal-contaminated sites in China for residential land $\left(\mathrm{Zn}<500 \mathrm{mg} \mathrm{kg}^{-1}, \mathrm{DB} 43 / \mathrm{T} 1165\right)$. This result implies that the $\mathrm{Zn}$ in remediated soils is well consolidated through thermal curing to realize brownfield-site heavy metal pollution

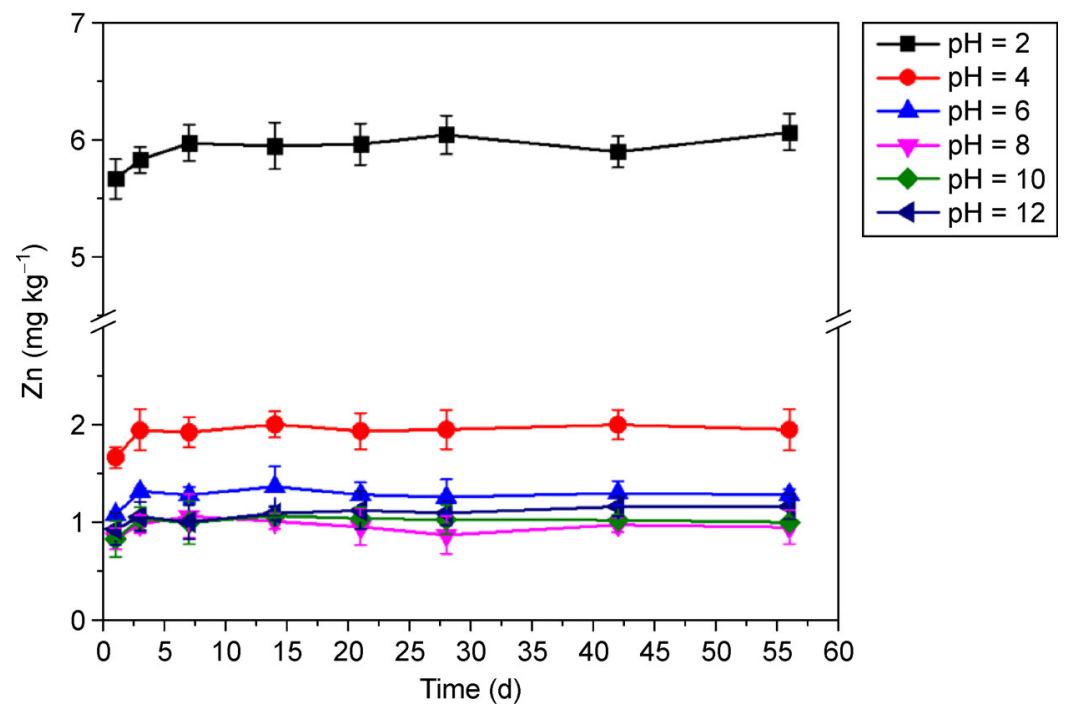

Fig. 1 Leaching characteristics of $\mathrm{Zn}$ in remediated soil at different values of the leaching agent $\mathrm{pH}$. 
remediation. With the continuous formation of $\mathrm{ZnCr}_{2} \mathrm{O}_{4}$ spinel, the leachability of $\mathrm{Zn}^{2+}$ was reduced significantly due to its incorporation into the spinel crystal structure (Tang et al., 2011; Snellings, 2015). Additionally, with a decrease in the leaching agent $\mathrm{pH}$ value, the leaching amount of $\mathrm{Zn}$ increased significantly, which reflected the short-term leaching characteristics and inherent resistance to acidic attack of the remediated soil. Moreover, strong acid conditions could promote the release of $\mathrm{Zn}^{2+}$; however, such a release did
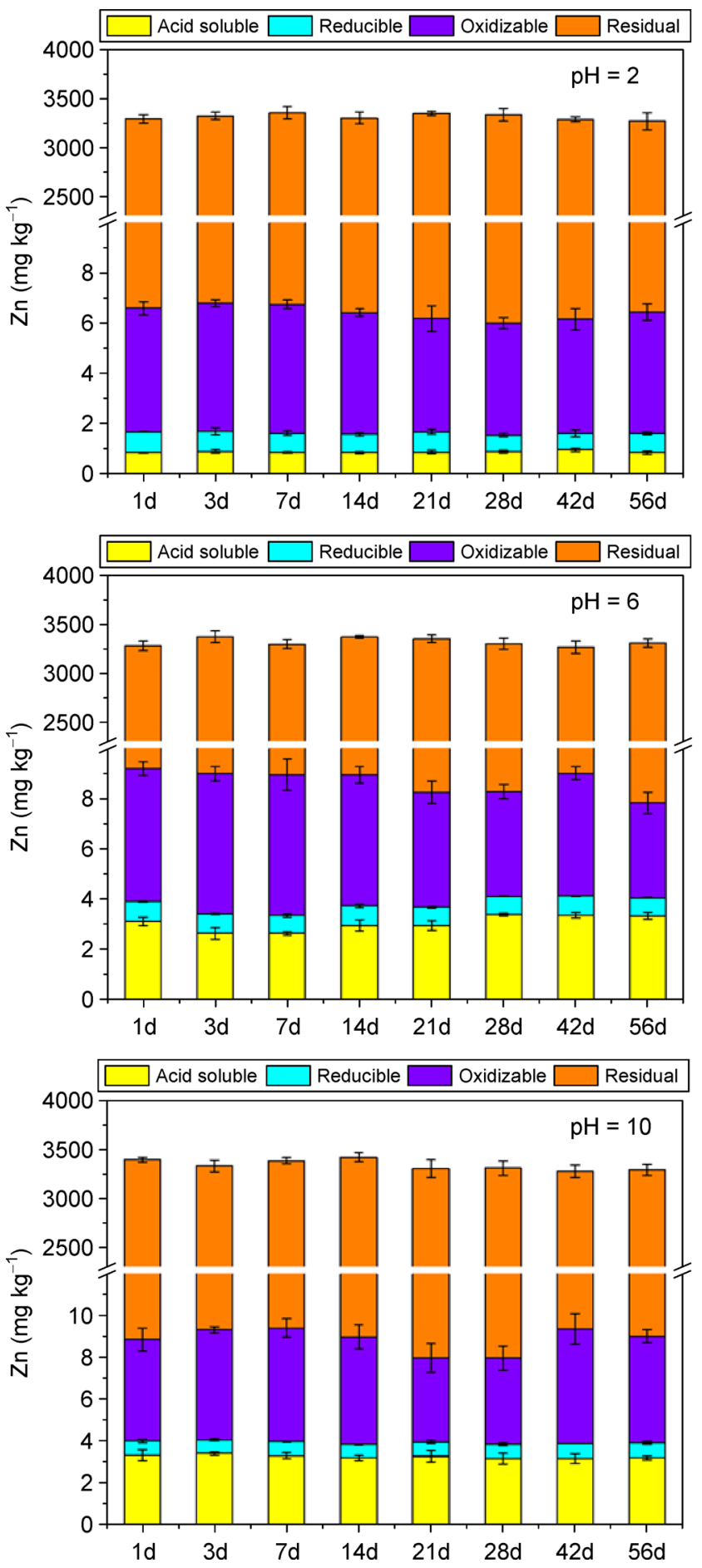

Fig. 2 Fraction distribution characteristics of $\mathrm{Zn}$ in remediated soil. not change significantly as the leaching time elapsed, which reflected the leaching stability of the remediated soil subjected to thermal curing.

The geochemical fraction distribution characteristics of $\mathrm{Zn}$ in the samples after the completion of the $\mathrm{pH}$-dependent leaching procedure are presented in Fig. 2. The $B C R$ sequential extraction procedure results showed that the contents of $\mathrm{Zn}$ in the acid-soluble fraction, reducible fraction, oxidizable fraction, and residual fraction were
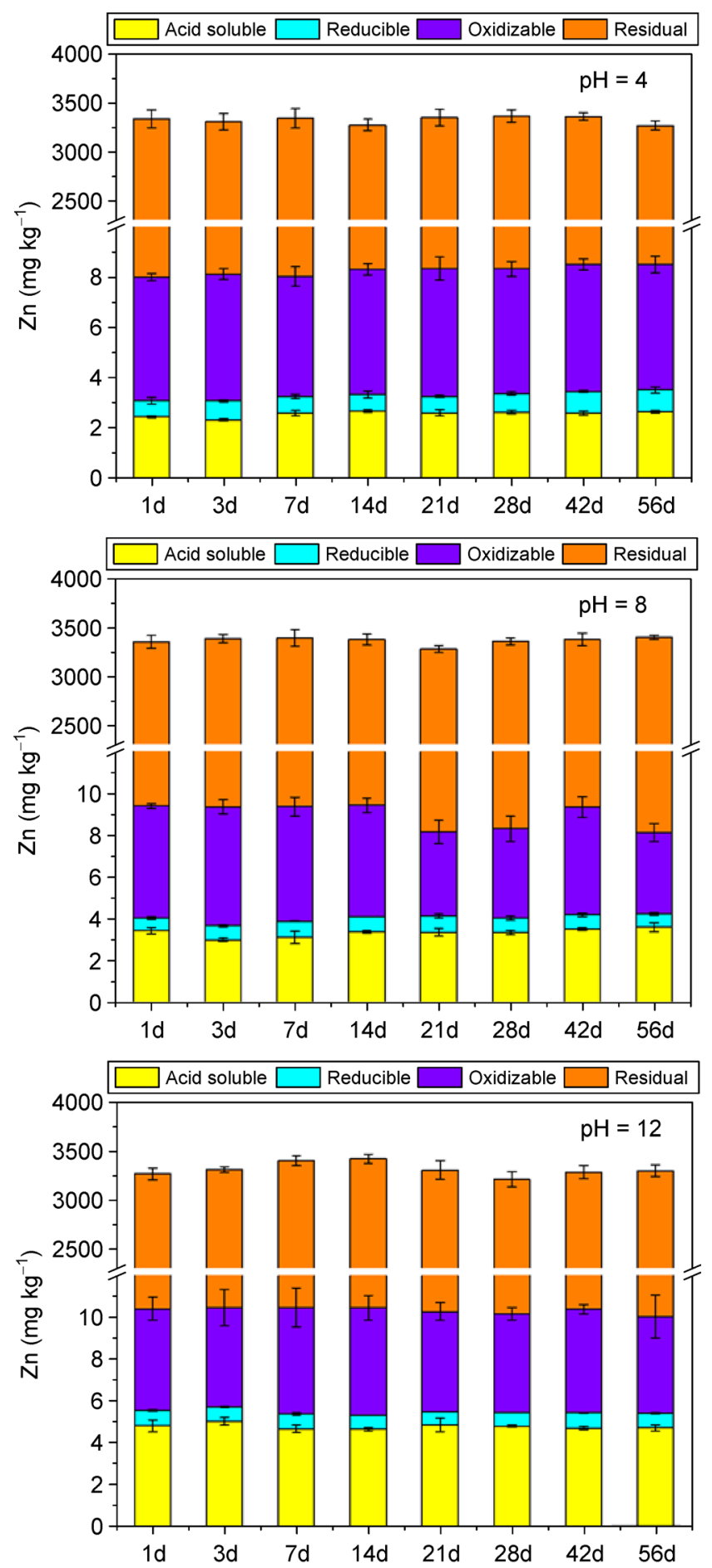
$0.85-4.77 \mathrm{mg} \mathrm{kg}^{-1}, 0.69-0.76 \mathrm{mg} \mathrm{kg}^{-1}, 4.82-5.00 \mathrm{mg} \mathrm{kg}^{-1}$ and $3308.20-3357.42 \mathrm{mg} \mathrm{kg}^{-1}$, respectively, at different leaching agent $\mathrm{pH}$ values. The composition of the four $\mathrm{Zn}$ fractions in the remediated soil showed that the content of the residual fraction was significantly higher than those of the other three fractions. With the formation of $\mathrm{ZnCr}_{2} \mathrm{O}_{4}$ spinel during the thermal curing sintering process, most of the acid-soluble fraction in the samples was converted into the three other, more stable fractions.

Furthermore, the Pearson correlation analysis showed that the leaching content $\left(R^{2}=-0.750\right)$ and acid-soluble fraction content $\left(R^{2}=0.915\right)$ of $Z n$ in the samples exhibited a strong relationship with the $\mathrm{pH}$ value of the leaching agent (Table 2). Moreover, a strong inverse correlation was observed between the leaching content and acid-soluble fraction content $\left(R^{2}=\right.$ -0.850 ), which reflected a strong complementary relationship between these two parameters. More importantly, the $\mathrm{pH}$ value of the leaching agent mainly affected the leaching content and acid-soluble fraction content and did not significantly influence the other three fractions. This effect reflected the long-term release and fraction distribution characteristics of $\mathrm{Zn}$ in the remediated soil. Under the action of a strong acid leaching agent, the large amount of $\mathrm{Zn}^{2+}$ adsorbed on the surface of the remediated soil leached out rapidly in the first leaching step, which included a certain amount of $\mathrm{Zn}^{2+}$ in the form of the acid-soluble fraction. Furthermore, in the second extraction step, the content of the acid-soluble fraction in the remediated soil correspondingly decreased. Conversely, the decrease in the leaching content in the first leaching step led to an increase in the acid-soluble content in the second extraction step. Therefore, these two parameters exhibited a complementary relationship, which also provided a theoretical basis for the environmental risk assessment in remediated soils.

3.2 Two-step calculation method to determine the risk value of remediated soil

The $\mathrm{pH}$ value is the most important factor in the natural environment and can affect the release of heavy metals in soil (Komonweeraket et al., 2015). Numerous studies have demonstrated that extremely acidic or alkaline conditions promote the release of heavy metals in soil (Kogbara et al.,
2012; Król et al., 2020). In accordance, the experimental results of this study showed that the leaching agent $\mathrm{pH}$ value directly affected the leaching content and acid-soluble fraction of remediated soil subjected to thermal curing (Figs. 1 and 2).

The biological toxicity of heavy metals is related not only to their leaching amount but also to the geochemical fraction distribution. This distribution directly affects the migration and circulation of heavy metals in the environment (Palleiro et al., 2016). Consequently, analyzing the heavy metal geochemical fraction distribution is valuable and can help distinguish the bioavailability and effect of heavy metals in remediated soil (Arunachalam et al., 1996; Saleem et al., 2018). Among the four geochemical fractions, the acid-soluble fraction metal, which is adsorbed on the soil component, poses the highest risk to the environment but is most often ignored. Therefore, it is desirable to account for this parameter in the present remediation soil risk assessment system. The other three fractions are relatively stable and unlikely to be released from samples even under extreme conditions (Pérez-Moreno et al., 2018). Therefore, it is necessary to propose a more suitable method than the traditional one-step method for risk value calculation by incorporating the acid-soluble fraction distribution characteristics of remediated soil in the calculation system.

Notably, as the $\mathrm{pH}$ increases from 2 to 12 , the sum of the leaching content and acid-soluble fraction content becomes $6.78,4.46,4.29,4.26,4.25$ and $5.84 \mathrm{mg} \mathrm{kg}^{-1}$ (Fig. 3). The sum of the leaching content and acid-soluble fraction content is significantly higher than the leaching content. This phenomenon is even more pronounced under alkaline conditions. Especially under strong alkali conditions $(\mathrm{pH}=10$ and $\mathrm{pH}=$ 12 ), the sum of the leaching content and acid-soluble fraction content is 4.2 and 5.3 times as high as the leaching content, respectively. In such a scenario, if we use the traditional onestep calculation method, which only calculates the leaching content of heavy metals to evaluate the risk of remediated soils, the risk may be significantly underestimated. In addition, under the condition of a strong alkali environment, the heavy metals in remediated soils do not leach over a short period of time, although they are still stored in the soils in the form of the acid-soluble fraction. These heavy metals may be released in the future, considering a long time scale; therefore, it is necessary to consider the potential release risk of such

Table 2 Correlation relationship of the leaching agent $\mathrm{pH}$ values, leaching contents and four fractions of $\mathrm{Zn}$.

\begin{tabular}{lllllll}
\hline $\begin{array}{l}\text { Correlation } \\
\text { relationship }\end{array}$ & $\begin{array}{l}\text { Leaching agent } \\
\mathrm{pH} \text { value }\end{array}$ & $\begin{array}{l}\text { Leaching } \\
\text { content }\end{array}$ & $\begin{array}{l}\text { Acid soluble } \\
\text { fraction }\end{array}$ & $\begin{array}{l}\text { Reducible } \\
\text { fraction }\end{array}$ & $\begin{array}{l}\text { Oxidizable } \\
\text { fraction }\end{array}$ & $\begin{array}{l}\text { Residual } \\
\text { fraction }\end{array}$ \\
\hline Leaching agent $\mathrm{pH}$ value & 1 & $-0.750^{* *}$ & $0.915^{* *}$ & $-0.378^{* *}$ & 0.020 & 0.088 \\
Leaching content & $-0.750^{* *}$ & 1 & $-0.850^{* *}$ & 0.231 & -0.079 & -0.143 \\
Acid soluble fraction & $0.915^{* *}$ & $-0.850^{* *}$ & 1 & $-0.309^{*}$ & -0.031 & 0.023 \\
Reducible fraction & $-0.378^{* *}$ & 0.231 & $-0.309^{*}$ & 1 & 0.120 & -0.206 \\
Oxidizable fraction & 0.020 & -0.079 & -0.031 & 0.120 & 1 & 0.223 \\
Residual fraction & 0.088 & -0.143 & 0.023 & -0.206 & 0.223 & 1 \\
\hline
\end{tabular}

** Significantly correlated at the 0.01 level (both sides). * Significantly correlated at the 0.05 level (both sides). 


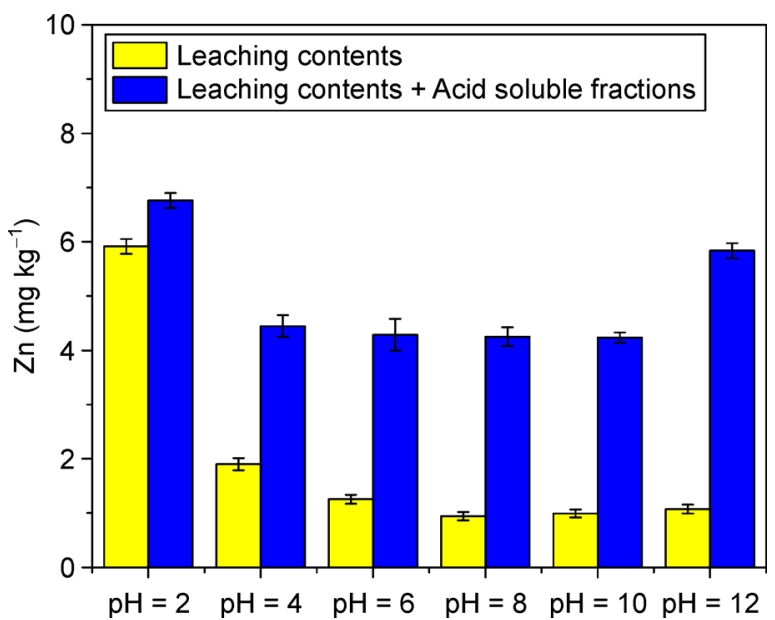

Fig. 3 Leaching and acid soluble fraction content characteristics of remediated soil at different values of the leaching agent $\mathrm{pH}$.

metals. Therefore, a two-step calculation method to calculate the sum of the leaching content and acid-soluble fraction content of heavy metals may be a better strategy to reasonably assess the potential risk value in a complex actual environment.

The risk value can be calculated as follows:

$$
C_{\text {risk }}=C_{\text {leaching }}+C_{\text {acid }}
$$

where $C_{\text {risk }}, C_{\text {leaching }}$ and $C_{\text {acid }}$ represent the risk value, leaching content and acid-soluble fraction content of the remediated soil samples, respectively. Thus, the proposed approach can effectively avoid the underestimation of the risk, as in the traditional one-step calculation method.

\subsection{Evaluation of ecological risk for remediated soil}

By incorporating the variation characteristics of the leaching content and acid-soluble fraction content, the risk value $\left(C_{\text {risk }}\right)$ was obtained through $\mathrm{pH}$-dependent leaching and the BCR extraction procedure. Subsequently, the risk assessment code model (RAC), which has been widely applied with the $B C R$ sequential extraction scheme to assess the ecological risks of heavy metals in soil, was modified and adopted to evaluate the ecological risks of remediated soil subjected to thermal curing (Nemati et al., 2011; Li et al., 2018). In this study, the modified ecological risk calculation model (MRAC) based on the RAC was used to calculate the level of risk. The MRAC can be calculated as follows:

$$
\mathrm{R}_{\text {ecological }}=C_{\text {risk }} /\left(C_{\text {risk }}+C_{\text {reducible }}+C_{\text {oxidizable }}+C_{\text {residual }}\right)
$$

In the formula, $\mathrm{R}_{\text {ecological }}$ denotes the ecological risk of the sample; and $C_{\text {risk }}, C_{\text {reducible }}, C_{\text {oxidizable }}$ and $C_{\text {residual }}$ represent the risk value and reducible fraction, oxidizable fraction and residual fraction contents, respectively. The five classifications in MRAC include a safe level (less than 1\%), low-risk level $(1 \%-10 \%)$, medium-risk level $(10 \%-30 \%)$, high-risk level (30\%-50\%) and very high-risk level (over 50\%) (Jain, 2004; Tong et al., 2020).

Based on the one-step and two-step calculation methods, the ecological risks of the remediated soil were evaluated using the MRAC method. The results showed that in the case of the one-step calculation method, the ecological risks of $\mathrm{Zn}$ in the remediated soil samples were $0.18 \%, 0.06 \%, 0.04 \%$, $0.03 \%, 0.03 \%$ and $0.03 \%$ at $\mathrm{pH}=2$ to $\mathrm{pH}=12$. However, when the two-step calculation method was used, the ecological risks of $\mathrm{Zn}$ were $0.20 \%, 0.13 \%, 0.13 \%, 0.13 \%$, $0.13 \%$ and $0.18 \%$ at $\mathrm{pH}=2$ to $\mathrm{pH}=12$ (Fig. 4). The ecological risks of $\mathrm{Zn}$ in the remediated soil calculated using the two calculation methods corresponded to a safe level. However, the ecological risk results calculated using the two-step calculation method were significantly higher than those calculated using the one-step calculation method. This discrepancy was especially true under strong alkali conditions $(\mathrm{pH}=10$ and $\mathrm{pH}=12)$, in which the ecological risk value increased by 4.3 times and 6 times, respectively. Compared with the one-step calculation method, the results of the twostep calculation method were more conservative and conducive to facilitate the environmental protection of remediated soils at reuse sites.

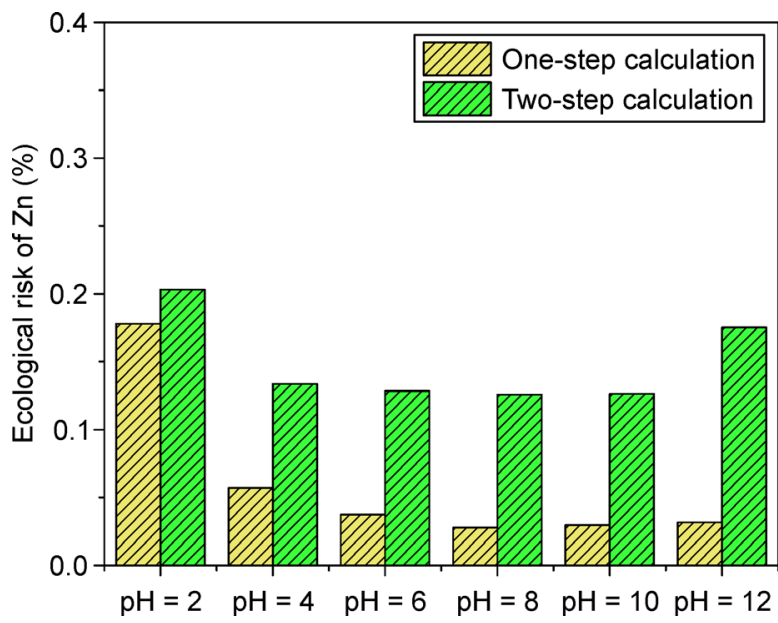

Fig. 4 Ecological risk of $\mathrm{Zn}$ in remediated soil.

\subsection{Evaluation of the human health risk of remediated soil}

The risk value $\left(C_{\text {risk }}\right)$ obtained through the systematic $\mathrm{pH}$-dependent leaching and BCR extraction procedure can be combined with a human health risk evaluation model to calculate the human health risk of remediated soil. In this study, the human health risk evaluation model proposed by the technical guidelines for the risk assessment of soil contamination of land for construction in China ( $\mathrm{HJ}$ 25.32019) was used. This model is usually divided into two parts: cancer and noncancer submodels (Hu et al., 2017; Wang et al., 2020). Since heavy metals are nongaseous pollutants, the human health risks of heavy metals in the remediated soil are primarily attributed to oral ingestion, skin contact, and direct inhalation. We considered two types of reuse issues 
represented by residential and industrial scenarios.

For the residential scenario, the carcinogenic effect of heavy metals and lifetime hazards of exposure to children and adults were considered. For the noncarcinogenic effect of heavy metals, the harm to the children upon exposure was considered. The calculation formulas related to the oral intake, skin contact and direct inhalation are as follows:

Risk from oral intake of remediated soil:

OISER $_{\mathrm{ca}}=C_{\text {risk }} \times S_{\mathrm{Fo}}$

$$
\begin{aligned}
& \times\left(\frac{O S I R_{\mathrm{c}} \times E D_{\mathrm{c}} \times E F_{\mathrm{c}}}{B W_{\mathrm{c}} \times A T_{\mathrm{ca}}}+\frac{O S I R_{\mathrm{a}} \times E D_{\mathrm{a}} \times E F_{\mathrm{a}}}{B W_{\mathrm{a}} \times A T_{\mathrm{ca}}}\right) \\
& \times \mathrm{ABS}_{\mathrm{o}} \times 10^{-6}
\end{aligned}
$$

$$
\begin{aligned}
\operatorname{OISER}_{\mathrm{nc}}= & \frac{C_{\mathrm{risk}}}{R f D_{\mathrm{o}} \times S A F} \times \frac{O S I R_{\mathrm{c}} \times E D_{\mathrm{c}} \times E F_{\mathrm{c}}}{B W_{\mathrm{c}} \times A T_{\mathrm{nc}}} \times \mathrm{ABS}_{\mathrm{o}} \\
& \times 10^{-6}
\end{aligned}
$$

Risk from skin contact of remediated soil:

$\operatorname{DCSER}_{\mathrm{ca}}=C_{\text {risk }} \times S_{\mathrm{Fd}}$

$$
\begin{aligned}
& \times\left(\frac{S A E_{\mathrm{c}} \times S S A R_{\mathrm{c}} \times E F_{\mathrm{c}} \times E D_{\mathrm{c}} \times E_{\mathrm{v}} \times A B S_{\mathrm{d}}}{B W_{\mathrm{c}} \times A T_{\mathrm{ca}}} \times 10^{-6}\right. \\
& \left.+\frac{S A E_{\mathrm{a}} \times S S A R_{\mathrm{a}} \times E F_{\mathrm{a}} \times E D_{\mathrm{a}} \times E_{\mathrm{v}} \times A B S_{\mathrm{d}}}{B W_{\mathrm{a}} \times A T_{\mathrm{ca}}} \times 10^{-6}\right)
\end{aligned}
$$

$$
\begin{aligned}
\operatorname{DCSER}_{\mathrm{nc}}= & \frac{C_{\text {risk }}}{R f D_{\mathrm{d}} \times S A F} \\
& \times \frac{S A E_{\mathrm{c}} \times S S A R_{\mathrm{c}} \times E F_{\mathrm{c}} \times E D_{\mathrm{c}} \times E_{\mathrm{v}} \times A B S_{\mathrm{d}}}{B W_{\mathrm{c}} \times A T_{\mathrm{nc}}} \\
& \times 10^{-6}
\end{aligned}
$$

Risk from direct inhalation of remediated soil particles:

$$
\begin{aligned}
\operatorname{PISER}_{\mathrm{ca}}= & C_{\text {risk }} \times S_{\mathrm{Fi}} \times\left(\frac{P M_{10} \times D A I R_{\mathrm{c}} \times P I A F \times E D_{\mathrm{c}} \times\left(f_{s p o} \times E F O_{\mathrm{c}}+f_{s p i} \times E F I_{\mathrm{c}}\right)}{B W_{\mathrm{c}} \times A T_{\mathrm{ca}}} \times 10^{-6}\right. \\
& \left.+\frac{P M_{10} \times D A I R_{\mathrm{a}} \times P I A F \times E D_{\mathrm{a}} \times\left(f s p o \times E F O_{\mathrm{a}}+f_{s p i} \times E F I_{\mathrm{a}}\right)}{B W_{\mathrm{a}} \times A T_{\mathrm{ca}}} \times 10^{-6}\right) \\
\operatorname{PISER}_{\mathrm{nc}}= & \frac{C_{\mathrm{risk}}}{R f D_{\mathrm{i}} \times S A F} \times \frac{P M_{10} \times D A I R_{\mathrm{c}} \times P I A F \times E D_{\mathrm{c}} \times\left(f_{s p o} \times E F O_{\mathrm{c}}+f_{s p i} \times E F I_{\mathrm{c}}\right)}{B W_{\mathrm{c}} \times A T_{\mathrm{nc}}} \times 10^{-6}
\end{aligned}
$$

For the industrial scenario, for the carcinogenic and noncarcinogenic effects of heavy metals, the lifetime hazard and harm of human exposure in adulthood were considered, respectively.

Risk from oral intake of remediated soil:

$$
\begin{aligned}
\operatorname{OISER}_{\mathrm{ca}}= & C_{\mathrm{risk}} \times S_{\mathrm{Fo}} \times \frac{O S I R_{\mathrm{a}} \times E D_{\mathrm{a}} \times E F_{\mathrm{a}}}{B W_{\mathrm{a}} \times A T_{\mathrm{ca}}} \times \mathrm{ABS}_{\mathrm{o}} \\
& \times 10^{-6} \\
\text { OISER }_{\mathrm{nc}}= & \frac{C_{\text {risk }}}{R f D_{\mathrm{o}} \times S A F} \times \frac{O S I R_{\mathrm{a}} \times E D_{\mathrm{a}} \times E F_{\mathrm{a}}}{B W_{\mathrm{a}} \times A T_{\mathrm{nc}}} \times \mathrm{ABS}_{\mathrm{o}} \\
& \times 10^{-6}
\end{aligned}
$$

Risk from skin contact of remediated soil:

$$
\begin{aligned}
\operatorname{DCSER}_{\mathrm{ca}}= & C_{\text {risk }} \times S_{\mathrm{Fd}} \\
& \times \frac{S E A_{\mathrm{a}} \times S S A R_{\mathrm{a}} \times E F_{\mathrm{a}} \times E_{\mathrm{v}} \times A B S_{\mathrm{d}}}{B W_{\mathrm{a}} \times A T_{\mathrm{ca}}} \times 10^{-6} \\
\operatorname{DCSER}_{\mathrm{nc}}= & \frac{C_{\text {risk }}}{R f D_{\mathrm{o}} \times S A F} \\
& \times \frac{S E A_{\mathrm{a}} \times S S A R_{\mathrm{a}} \times E F_{\mathrm{a}} \times E D_{\mathrm{a}} \times E_{\mathrm{v}} \times A B S_{\mathrm{d}}}{B W_{\mathrm{a}} \times A T_{\mathrm{nc}}} \\
& \times 10^{-6}
\end{aligned}
$$

Risk from direct inhalation of remediated soil particles:

$$
\begin{gathered}
\operatorname{PISER}_{\mathrm{ca}}=C_{\text {risk }} \times S_{\mathrm{Fi}} \times \frac{P M_{10} \times D A I R_{\mathrm{a}} \times P I A F \times E D_{\mathrm{a}} \times\left(f_{\text {spo }} \times E F O_{\mathrm{a}}+f s p i \times E F I_{\mathrm{a}}\right)}{B W_{\mathrm{a}} \times A T_{\mathrm{ca}}} \times 10^{-6} \\
\mathrm{PISER}_{\mathrm{nc}}=\frac{C_{\mathrm{risk}}}{R f D_{\mathrm{i}} \times S A F} \times \frac{P M_{10} \times D A I R_{\mathrm{a}} \times P I A F \times E D_{\mathrm{a}} \times\left(f_{s p o} \times E F O_{\mathrm{a}}+f s p i \times E F I_{\mathrm{a}}\right)}{B W_{\mathrm{a}} \times A T_{\mathrm{nc}}} \times 10^{-6}
\end{gathered}
$$




$$
\begin{aligned}
& \mathrm{SAE}_{\mathrm{c}}=239 \times H_{\mathrm{c}}^{0.417} \times B W_{\mathrm{c}}^{0.517} \times S E R_{\mathrm{c}} \\
& \mathrm{SAE}_{\mathrm{a}}=239 \times H_{\mathrm{a}}^{0.417} \times B W_{\mathrm{a}}^{0.517} \times S E R_{\mathrm{a}}
\end{aligned}
$$

In the formulas, OISER ${ }_{\mathrm{ca}}$, DCSER $\mathrm{DCa}_{\mathrm{c}}$ and $\mathrm{PISER}_{\mathrm{ca}}$ represent the carcinogenic risk from oral intake, skin contact and direct inhalation, respectively, and $\operatorname{OISER}_{\mathrm{nc}}, \mathrm{DCSER}_{\mathrm{nc}}$, and PISER $_{n c}$ represent the noncarcinogenic risk from oral intake, skin contact and direct inhalation, respectively. For Zn, which is a noncarcinogen, only the noncarcinogenic effects were calculated in this evaluation. In general, the level of harm caused by human exposure to noncarcinogenic heavy metals through a single route is ultimately characterized by the hazard quotient. Furthermore, the level of human exposure to noncarcinogenic heavy metals is characterized by the sum of the hazard quotients of a population exposed to a single

\begin{tabular}{|c|c|c|c|c|}
\hline \multirow{2}{*}{$\begin{array}{l}\text { Exposure } \\
\text { parameter }\end{array}$} & \multirow[t]{2}{*}{ Description } & \multirow[t]{2}{*}{ Unit } & \multicolumn{2}{|c|}{ Reference value } \\
\hline & & & $\begin{array}{l}\text { Residential } \\
\text { scenario }\end{array}$ & $\begin{array}{l}\text { Industrial } \\
\text { scenario }\end{array}$ \\
\hline$O S I R_{\mathrm{C}}$ & Daily intake of contaminated soil by children & $\mathrm{mg} \mathrm{d}^{-1}$ & 200 & - \\
\hline$O S I R_{a}$ & Daily intake of contaminated soil by adults & $\mathrm{mg} \mathrm{d}^{-1}$ & 100 & 100 \\
\hline$E D_{\mathrm{c}}$ & Exposure duration of Children & a & 6 & - \\
\hline$E D_{\mathrm{a}}$ & Exposure duration of adults & a & 24 & 25 \\
\hline$E F_{\mathrm{c}}$ & Childhood exposure factor & $d / a$ & 350 & - \\
\hline$E F_{\mathrm{a}}$ & Adult exposure factor & $d / a$ & 350 & 250 \\
\hline$B W_{\mathrm{c}}$ & Childhood body weight & $\mathrm{kg}$ & 19.2 & - \\
\hline$B W_{\mathrm{a}}$ & Adult body weight & $\mathrm{kg}$ & 61.8 & 61.8 \\
\hline$A B S_{0}$ & Dermal absorption factor & - & 1 & 1 \\
\hline$A T_{\mathrm{ca}}$ & Average time of carcinogenic effects & $d$ & 27740 & 27740 \\
\hline$A T_{\mathrm{nc}}$ & Average time of noncarcinogenic effects & d & 2190 & 9125 \\
\hline$S S A R_{\mathrm{c}}$ & Soil adhesion coefficient of skin surface in children & $\mathrm{mg} / \mathrm{cm}$ & 0.2 & - \\
\hline$S S A R_{\mathrm{a}}$ & Soil adhesion coefficient of skin surface in adults & $\mathrm{mg} / \mathrm{cm}$ & 0.07 & 0.2 \\
\hline$A B S_{\mathrm{d}}$ & Skin contact absorption efficiency factor & - & 1 & 1 \\
\hline$E_{\mathrm{v}}$ & Frequency of daily skin contact events & $\mathrm{n} / \mathrm{d}$ & 1 & 1 \\
\hline$S A E_{\mathrm{c}}$ & Exposed skin surface area for children & $\mathrm{cm}^{2}$ & 2848 & - \\
\hline$S A E_{\mathrm{a}}$ & Exposed skin surface area for adults & $\mathrm{cm}^{2}$ & 5374 & 3023 \\
\hline$S E R_{\mathrm{c}}$ & Area ratio of exposed skin for children & - & 0.36 & - \\
\hline$S E R_{\mathrm{a}}$ & Area ratio of exposed skin for adults & - & 0.32 & 0.18 \\
\hline SAF & Reference dose coefficient for exposure to soil & - & 1 & 1 \\
\hline$H_{\mathrm{c}}$ & Average height of children & $\mathrm{cm}$ & 113.15 & - \\
\hline$H_{\mathrm{a}}$ & Average height of adults & $\mathrm{cm}$ & 161.5 & 161.5 \\
\hline $\mathrm{PM}_{10}$ & Amount of particulate matter in the air & $\mathrm{mg} \mathrm{cm}^{-3}$ & 0.119 & 0.119 \\
\hline$D A I R_{\mathrm{c}}$ & Daily air breathing volume for children & $m^{3} d^{-1}$ & 7.5 & - \\
\hline$D A I R_{\mathrm{a}}$ & Daily air breathing volume for adults & $m^{3} d^{-1}$ & 14.5 & 14.5 \\
\hline PIAF & Retention rate of particulate matter in the body & - & 0.75 & 0.75 \\
\hline fspi & Indoor air comes from the proportion of particulate matter & - & 0.8 & 0.8 \\
\hline fspo & Outdoor air comes from the proportion of particulate matter & - & 0.5 & 0.5 \\
\hline$E F O_{\mathrm{c}}$ & Outdoor exposure frequency for children & $d / a$ & 87.5 & - \\
\hline$E F O_{a}$ & Outdoor exposure frequency for adults & $d / a$ & 87.5 & 62.5 \\
\hline$E F I_{\mathrm{C}}$ & Indoor exposure frequency for children & $d / a$ & 262.5 & - \\
\hline$E F l_{a}$ & Indoor exposure frequency for adults & $d / a$ & 262.5 & 187.5 \\
\hline
\end{tabular}

Table 3 Exposure parameters and reference values for human health risk calculation. 
Table 4 Noncarcinogenic reference dose and carcinogenic slope factor for different heavy metals.

\begin{tabular}{|c|c|c|c|c|c|c|}
\hline \multirow{2}{*}{ Heavy metal } & \multicolumn{3}{|c|}{ Noncarcinogenic reference dose $\left(\mathrm{mg} \mathrm{kg}^{-1} \mathrm{~d}^{-1}\right)$} & \multicolumn{3}{|c|}{ Carcinogenic slope factor $\left(\mathrm{mg} \mathrm{kg}^{-1} \mathrm{~d}^{-1}\right)$} \\
\hline & Oral $\left(R f D_{\mathrm{o}}\right)$ & Skin $\left(R f D_{\mathrm{d}}\right)$ & Inhalation $\left(R f D_{\mathrm{i}}\right)$ & Oral $\left(S_{\mathrm{Fo}}\right)$ & $\operatorname{Skin}\left(S_{\mathrm{Fd}}\right)$ & Inhalation $\left(S_{\mathrm{Fi}}\right)$ \\
\hline $\mathrm{Cu}$ & 4.00E-02 & 4.00E-02 & - & - & - & - \\
\hline $\mathrm{Zn}$ & $3.00 \mathrm{E}-01$ & $3.00 \mathrm{E}-01$ & $3.00 \mathrm{E}-01$ & - & - & - \\
\hline $\mathrm{Pb}$ & $1.40 \mathrm{E}-04$ & 1.40E-04 & - & - & - & - \\
\hline $\mathrm{Cd}$ & 3.00E-03 & 2.50E-05 & 5.71E-05 & - & - & $6.30 E+00$ \\
\hline $\mathrm{Ni}$ & 2.00E-02 & 8.00E-04 & 2.06E-02 & $1.70 E+00$ & $4.25 E+00$ & 9.01E-01 \\
\hline As & 3.00E-04 & 3.00E-04 & $3.00 E-04$ & $1.50 E+00$ & $3.66 E+00$ & $1.50 E+00$ \\
\hline $\mathrm{Cr}$ & $1.50 E+00$ & 1.95E-02 & 2.86E-05 & - & - & - \\
\hline $\mathrm{Hg}$ & $1.60 \mathrm{E}-04$ & 1.60E-04 & 8.75E-05 & - & - & - \\
\hline
\end{tabular}

heavy metal in multiple ways, namely, the hazard index. Finally, the acceptable hazard index for a single heavy metal must be less than 1. All the exposure parameters and reference values are presented in Tables 3 and 4 .

Based on the one-step and two-step risk value calculation methods, the human health risk of remediated soil was evaluated. The calculated human health risks of the remediated soil samples are shown in Fig. 5. The human health risks of remediated soils treated by thermal curing are less than 1 , which corresponds to the safe range. When using the one-step risk value calculation method, as the leaching agent $\mathrm{pH}$ value gradually increased, the human health risks of $\mathrm{Zn}$ gradually decreased. For the residential scenario, the hazard index of $\mathrm{Zn}$ was 2.15E-04, 6.94E-05, 4.58E-05, 3.44E-05, $3.61 \mathrm{E}-05$ and $3.88 \mathrm{E}-05$, and for the industrial scenario, the hazard index of $\mathrm{Zn}$ was 2.61E-05, 8.42E-06, 5.56E-06, 4.17E$06,4.38 \mathrm{E}-06$ and $4.72 \mathrm{E}-06$ at $\mathrm{pH}=2$ to $\mathrm{pH}=12$. When the two-step risk content calculation method was used, for the residential scenario, the hazard index of $\mathrm{Zn}$ was $2.45 \mathrm{E}-04$, 1.61E-04, 1.55E-04, 1.54E-04, 1.54E-04 and 2.12E-04, and for the industrial scenario, the hazard index of $\mathrm{Zn}$ was $2.98 \mathrm{E}$ $05,1.96 \mathrm{E}-05,1.89 \mathrm{E}-05,1.87 \mathrm{E}-05,1.87 \mathrm{E}-05$ and 2.57E-05 at

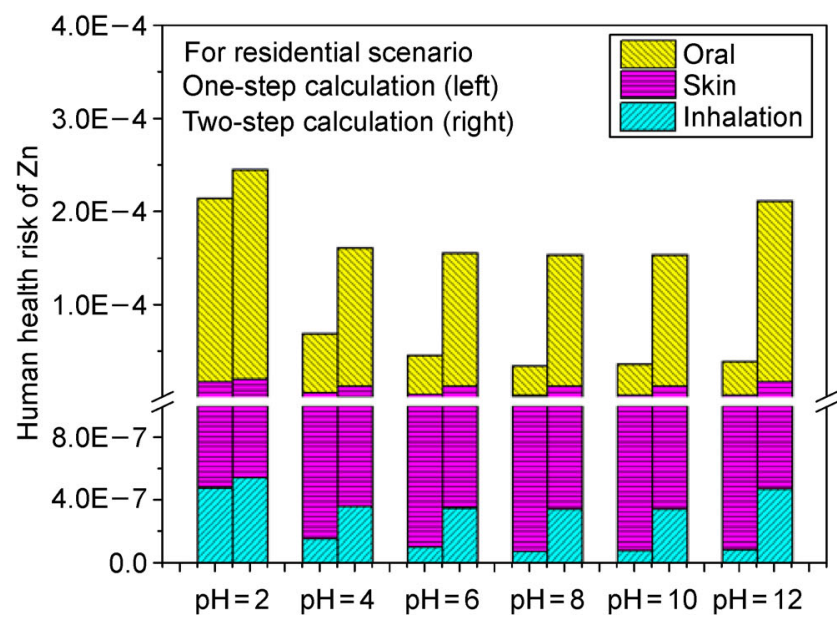

$\mathrm{pH}=2$ to $\mathrm{pH}=12$.

The human health risks determined using the two-step calculation method were higher than those obtained using the one-step calculation method. This aspect was especially true under strong alkali conditions $(\mathrm{pH}=10$ and $\mathrm{pH}=12)$, in which the human health risk value increased by 4.3 and 5.4 times for the residential and industrial scenarios, respectively. Notably, the parameter requirements of the industrial scenario are not as strict as those of the residential scenario in the latest technical guidelines for risk assessment of soil contamination of land for construction in China (HJ 25.3-2019). The calculated human health risks of the industrial scenario were lower than those of the residential scenario. The human health risk evaluation results of the two-step calculation method were more conservative than those of the one-step method. The two-step method can thus facilitate the protection of human health against remediated soils at reuse sites.

\section{Conclusions}

Remediated soil treated by thermal curing exhibited strong

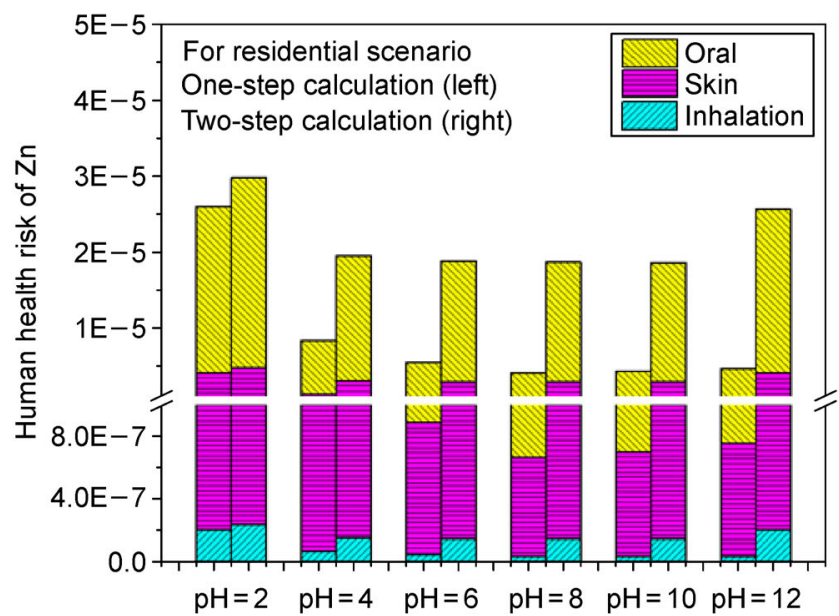

Fig. 5 Human health risk against $\mathrm{Zn}$ in remediated soil for residential and industrial scenarios. 
inherent resistance to acidic attack with the formation of $\mathrm{ZnCr}_{2} \mathrm{O}_{4}$ spinel. The fraction distribution characteristics of $\mathrm{Zn}$ in the remediated soil showed that the leaching agent $\mathrm{pH}$ value mainly affected the acid-soluble fraction content but did not significant influence the other three fractions. Moreover, a strong complementary relationship was observed between the leaching content and acid-soluble fraction content, which indicated that the sum of these two parameters is more representative than either individual parameter of the risk value of the remediated soil. Based on this characteristic, we proposed a two-step calculation method to calculate the sum of the leaching and acid-soluble fraction contents of heavy metals as the risk value of remediated soil treated by thermal curing. This method was further combined with the modified ecological risk evaluation model and human health risk evaluation model proposed by the technical guidelines for the risk assessment of soil contamination of land for construction in China to evaluate the ecological and human health risk of remediated soil. Compared with the traditional one-step calculation method, which considers only the leaching content as the risk value, this two-step calculation method can effectively avoid underestimating the risk of remediated soils, especially in alkaline conditions.

\section{Acknowledgments}

This study was financially supported by the National Key Research and Development Program of China (2018YFC1801402) and GDAS' Project of Science and Technology Development (2020GDASYL-20200103083 and 2020GDASYL20200301003).

\section{References}

Abbas, M., John, V., Rachel, E., 2018. Chromated copper arsenate timber: A review of products, leachate studies and recycling. Journal of Cleaner Production 179, 292-307.

Arunachalam, J., Emons, H., Krasnodebska, B., Mohl, C., 1996. Sequential extraction studies on homogenized forest soil samples. Science of the Total Environment 181, 147-159.

Bardos, R.P., Jones, S., Stephenson, I., Menger, P., Beumer, V., Neonato, F., Maring, L., Ferber, U., Track, T., Wendler, K., 2016. Optimising value from the soft re-use of brownfield sites. Science of the Total Environment 563-564, 769-782.

Chen, Y., Hipel, K.W., Kilgour, D.M., Zhu, Y., 2009. A strategic classification support system for brownfield redevelopment. Environmental Modelling \& Software 24, 647-654.

Ding, D., Song, X., Wei, C., LaChance, J., 2019. A review on the sustainability of thermal treatment for contaminated soils. Environmental Pollution 253, 449-463.

Dixit, T., Palani, I.A., Singh, V., 2015. Investigation on the influence of dichromate ion on the $\mathrm{ZnO}$ nano-dumbbells and $\mathrm{ZnCr}_{2} \mathrm{O}_{4}$ nanowalls. Journal of Materials Science Materials in Electronics 26, 821-829.

Fu, F.L., Xie, L.P., Tang, B., Wang, Q., Jiang, S.X., 2012. Application of a novel strategy-Advanced Fenton-chemical precipitation to the treatment of strong stability chelated heavy metal containing wastewater. Chemical Engineering Journal 189, 283-287.

Guo, B., Liu, B., Yang, J., Zhang, S., 2017. The mechanisms of heavy metal immobilization by cementitious material treatments and thermal treatments: A review. Journal of Environmental Management 193, 410-422.

Gupta, N., Gedam, V.V., Moghe, C., Labhasetwar, P., 2019. Comparative assessment of batch and column leaching studies for heavy metals release from Coal Fly Ash Bricks and Clay Bricks. Environmental Technology \& Innovation 16, 100461.

Hu, B., Wang, J., Jin, B., Li, Y., Shi, Z., 2017. Assessment of the potential health risks of heavy metals in soils in a coastal industrial region of the Yangtze River Delta. Environmental Science and Pollution Research International 24, 19816-19826.

Jain, C.K., 2004. Metal fractionation study on bed sediments of River Yamuna, India. Water Research 38, 569-578.

Khalid, S., Shahid, M., Niazi, N.K., Murtaza, B., Bibi, I., Dumat, C., 2017. A comparison of technologies for remediation of heavy metal contaminated soils. Journal of Geochemical Exploration 182, 247 268.

Kogbara, R.B., Al-Tabbaa, A., Yi, Y., Stegemann, J.A., 2012. pHdependent leaching behaviour and other performance properties of cement-treated mixed contaminated soil. Journal of Environmental Sciences (China) 24, 1630-1638.

Komonweeraket, K., Cetin, B., Aydilek, A.H., Benson, C.H., Edil, T.B., 2015. Effects of $\mathrm{pH}$ on the leaching mechanisms of elements from fly ash mixed soils. Fuel 140, 788-802.

Król, A., Mizerna, K., Bożym, M., 2020. An assessment of pHdependent release and mobility of heavy metals from metallurgical slag. Journal of Hazardous Materials 384, 121502.

Kumpiene, J., Lagerkvist, A., Maurice, C., 2008. Stabilization of As, $\mathrm{Cr}, \mathrm{Cu}, \mathrm{Pb}$ and $\mathrm{Zn}$ in soil using amendments-a review. Waste Management (New York, N.Y.) 28, 215-225.

Li, J., Yu, G., Xie, S., Pan, L., Li, C., You, F., Wang, Y., 2018. Immobilization of heavy metals in ceramsite produced from sewage sludge biochar. Science of the Total Environment 628$629,131-140$.

Li, J.I., Hashaimoto, Y., Riya, S., Terada, A., Hou, H., Shibagaki, Y., Hosomi, M., 2019. Removal and immobilization of heavy metals in contaminated soils by chlorination and thermal treatment on an industrial-scale. Chemical Engineering Journal 359, 385-392.

Li, X., He, C., Bai, Y., Ma, B., Wang, G., Tan, H., 2014. Stabilization/ solidification on chromium (III) wastes by $\mathrm{C}(3) \mathrm{A}$ and $\mathrm{C}(3) \mathrm{A}$ hydrated matrix. Journal of Hazardous Materials 268, 61-67.

Liu, L., Li, W., Song, W., Guo, M., 2018. Remediation techniques for heavy metal-contaminated soils: Principles and applicability. Science of the Total Environment 633, 206-219.

Luo, X.S., Yu, S., Zhu, Y.G., Li, X.D., 2012. Trace metal contamination in urban soils of China. Science of the Total Environment 421-422, 17-30.

Mahedi, M., Cetin, B., 2019. Leaching of elements from cement activated fly ash and slag amended soils. Chemosphere 235, 565574.

Malviya, R., Chaudhary, R., 2006. Factors affecting hazardous waste solidification/stabilization: a review. Journal of Hazardous Materi- 
als $137,267-276$.

Marinković, Z., Mančić, L., Vulić, P., Milošević, O., 2004. The influence of mechanical activation on the stoichiometry and defect structure of a sintered $\mathrm{ZnO}-\mathrm{Cr}_{2} \mathrm{O}_{3}$ system. Materials Science Forum 453 454, 423-428.

Nemati, K., Abu Bakar, N.K., Abas, M.R., Sobhanzadeh, E., 2011. Speciation of heavy metals by modified BCR sequential extraction procedure in different depths of sediments from Sungai Buloh, Selangor, Malaysia. Journal of Hazardous Materials 192, 402-410.

Palleiro, L., Patinha, C., Rodriguez-Blanco, M.L., Taboada-Castro, M. M., Taboada-Castro, M.T., 2016. Metal fractionation in topsoils and bed sediments in the Mero River rural basin: Bioavailability and relationship with soil and sediment properties. Catena 144, 34-44.

Pardo, R., Helena, B.A., Cazurro, C., Guerra, C., Deban, L., Guerra, C.M., Vega, M., 2004. Application of two- and three-way principa component analysis to the interpretation of chemical fractionation results obtained by the use of the BCR procedure. Analytica Chimica Acta 523, 125-132.

Pérez-Moreno, S.M., Gázquez, M.J., Pérez-López, R., Bolivar, J.P., 2018. Validation of the BCR sequential extraction procedure for natural radionuclides. Chemosphere 198, 397-408.

Pueyo, M., Mateu, J., Rigol, A., Vidal, M., López-Sánchez, J.F., Rauret, G., 2008. Use of the modified BCR three-step sequential extraction procedure for the study of trace element dynamics in contaminated soils. Environmental Pollution 152, 330-341.

Sahuquillo, A., Lopez-Sanchez, J.F., Rubio, R., Rauret, G., Thomas, R.P., Davidson, C.M., Ure, A.M., 1999. Use of a certified reference material for extractable trace metals to assess sources of uncertainty in the BCR three-stage sequential extraction procedure. Analytica Chimica Acta 382, 317-327.

Saleem, M., Iqbal, J., Akhter, G., Shah, M.H., 2018. Fractionation, bioavailability, contamination and environmental risk of heavy metals in the sediments from a freshwater reservoir, Pakistan. Journal of Geochemical Exploration 184, 199-208.

Samaksaman, U., Peng, T.H., Kuo, J.H., Lu, C.H., Wey, M.Y., 2016. Thermal treatment of soil co-contaminated with lube oil and heavy metals in a low-temperature two-stage fluidized bed incinerator. Applied Thermal Engineering 93, 131-138.

Shih, K., White, T., Leckie, J.O., Kaimin, S., Tim, W., James, O.L., 2006. Nickel stabilization efficiency of aluminate and ferrite spinels and their leaching behavior. Environmental Science \& Technology $40,5520-5526$

Shih, K.M., Tang, Y.Y., 2012. Incorporating simulated zinc ash by kaolinite- and sludge-based ceramics: Phase transformation and product leachability. Chinese Journal of Chemical Engineering 20 $411-416$

Snellings, R., 2015. Surface chemistry of calcium aluminosilicate glasses. Journal of the American Ceramic Society 98, 303-314.

Solid waste-extraction procedure for leaching toxicity-sulphuric acid \& nitric acid method. 2007. China, HJ/T299-2007.

Standards for Soil Remediation of Heavy Metal Contaminated Sites. 2016. China, DB43/T1165.

Stephen, S.E., Lawrence, L.M., Roy, R.A., Wallace, W.D., 2007. Thermodynamics of $\mathrm{Cr}_{2} \mathrm{O}_{3}, \mathrm{FeCr}_{2} \mathrm{O}_{4}, \mathrm{ZnCr}_{2} \mathrm{O}_{4}$, and $\mathrm{CoCr}_{2} \mathrm{O}_{4}$. Journal of Chemical Thermodynamics 39, 1474-1492.
Sun, Y., Li, H., Guo, G., Semple, K.T., Jones, K.C., 2019. Soil contamination in China: Current priorities, defining background levels and standards for heavy metals. Journal of Environmental Management 251, 109512.

Sutherland, R.A., 2010. BCR $®-701$ : a review of 10-years of sequential extraction analyses. Analytica Chimica Acta 680, 10-20.

Taha, Y., Benarchid, Y., Benzaazoua, M., 2019. Environmental behavior of waste rocks based concrete: Leaching performance assessment. Resources Policy, 101419.

Taha, Y., Benzaazoua, M., Edahbi, M., Mansori, M., Hakkou, R., 2018. Leaching and geochemical behavior of fired bricks containing coal wastes. Journal of Environmental Management 209, 227-235.

Tang, Y., Chan, S.W., Shih, K., 2014. Copper stabilization in beneficial use of waterworks sludge and copper-laden electroplating sludge for ceramic materials. Waste Management (New York, N.Y.) 34, 1085-1091.

Tang, Y., Shih, K., Wang, Y., Chong, T.C., 2011. Zinc stabilization efficiency of aluminate spinel structure and its leaching behavior. Environmental Science \& Technology 45, 10544-10550.

Tang, Y.Y., Shih, K., Li, M., Wu, P.F., 2016. Zinc immobilization in simulated aluminum-rich waterworks sludge systems. Procedia Environmental Sciences 31, 691-697.

Technical guidelines for risk assessment of soil contamination of land for construction. 2019. China, HJ 25.3-2019.

Tong, L., He, J., Wang, F., Wang, Y., Wang, L., Tsang, D.C.W., Hu, Q., Hu, B., Tang, Y., 2020. Evaluation of the BCR sequential extraction scheme for trace metal fractionation of alkaline municipal solid waste incineration fly ash. Chemosphere 249, 126115.

Vareda, J.P., Valente, A.J.M., Durães, L., 2019. Assessment of heavy metal pollution from anthropogenic activities and remediation strategies: A review. Journal of Environmental Management 246, 101-118.

Wang, S., Kalkhajeh, Y.K., Qin, Z., Jiao, W., 2020. Spatial distribution and assessment of the human health risks of heavy metals in a retired petrochemical industrial area, south China. Environmental Research 188, 109661.

Wang, Y., Li, F., Song, J., Xiao, R., Luo, L., Yang, Z., Chai, L., 2018. Stabilization of $\mathrm{Cd}-, \mathrm{Pb}-, \mathrm{Cu}-$ and $\mathrm{Zn}$-contaminated calcareous agricultural soil using red mud: a field experiment. Environmental Geochemistry and Health 40, 2143-2153.

Wu, F., Tang, Y.Y., Lu, X.W., Liu, C.S., Lv, Y.H., Tong, H., Ning, Z.P., Liao, C.Z., Li, F.B., 2019. Simultaneous immobilization of Zn(II) and $\mathrm{Cr}(\mathrm{III})$ in spinel crystals from beneficial utilization of waste brownfield-site soils. Clays and Clay Minerals 67, 315-324.

Xie, S., Yang, F., Feng, H., Wei, C., Wu, F., 2019. Assessment of potential heavy metal contamination in the peri-urban agricultural soils of 31 provincial capital cities in China. Environmental Management 64, 366-380.

Yang, Q., Li, Z., Lu, X., Duan, Q., Huang, L., Bi, J., 2018. A review of soil heavy metal pollution from industrial and agricultural regions in China: Pollution and risk assessment. Science of the Total Environment 642, 690-700.

Yao, Z.T., Li, J.H., Xie, H.H., Yu, C.H., 2012. Review on remediation technologies of soil contaminated by heavy metals. Procedia Environmental Sciences 16, 722-729. 
Zhang, Y., Gao, W., Ni, W., Zhang, S., Li, Y., Wang, K., Huang, X., Fu, P., Hu, W., 2020. Influence of calcium hydroxide addition on arsenic leaching and solidification/stabilisation behaviour of metallurgical-slag-based green mining fill. Journal of Hazardous Materials 390, 122161.

Zhou, C.L., Ge, S.F., Yu, H., Zhang, T.Q., Cheng, H.L., Sun, Q., Xiao,
R., 2018. Environmental risk assessment of pyrometallurgical residues derived from electroplating and pickling sludges. Journal of Cleaner Production 177, 699-707.

Zhou, G.Z., Yin, X., Zhou, J., Cheng, W.Y., 2017. Speciation and spatial distribution of $\mathrm{Cr}$ in chromite ore processing residue site, Yunnan, China. Acta Geochimica 36, 291-297. 